\title{
Chores, Medicine for a Widespread Lack of Gratitude in the One-child Generations of China
}

\author{
Shi Li \\ School of Arts, University of New England, Australia
}

Copyright $(2016$ by authors, all rights reserved. Authors agree that this article remains permanently open access under the terms of the Creative Commons Attribution License 4.0 International License

\begin{abstract}
Little emperors" and "little princesses" are not new terms for describing the young generations of China after the 36-years' implementation of its one-child policy from 1979 that has triggered the launch of wave upon wave of massive and long-lasting campaigns of gratitude education at all levels of schools cross China from 2005 up to the present. Yet, on $10^{\text {th }}$ December 2015, the People's Daily Online, an official newspaper flagship of China, reported that a lack of gratitude in young generations came out top of a list of the top ten deficiencies of Chinese people. What went wrong with the Chinese young generations and China's gratitude education? This article employs the morality of justice theory to explore the crux of a widespread lack of gratitude in young Chinese generations with the main focus on the role of chores in child development.
\end{abstract}

Keywords Chores, One-child Policy, Lack of Gratitude, Gratitude Education, Gratitude Development, Filial Piety, Morality of Justice, Parental Love, Induction, Discipline

\section{Background}

The one-child policy, first instituted in late 1979, had put the only child of a family under the care of the six elders (2 parents and 4 grandparents), in particular, their parents, which resulted in the "me generations". These parents who had experienced very harsh lives, including, for example, living through the Three Years of Great Chinese Famine (1959-1961) and the Cultural Revolution (1966-1976), worked very hard, with overwhelming dedication to their only children ensuring that "no matter how much shame and suffering I have to go through for him, as long as I live I'll never let him know hunger or pain of any kind. I will never, ever let him suffer what I have been through - I would give my life for him" [1]. As a result, these children were indulged in all the rights and benefits of a family as best their parents could provide, but took no family responsibilities of any kind, in particular, sharing no chores. A number of surveys [2-6] measuring gratitude in China's young generations all revealed a prevalent lack of gratitude in these children towards their parents. For example, Li and Peng's [3] survey of a total of 485 middle school students in an urban area found that $100 \%$ of them believed that gratitude was not relevant to them at their age, and $30 \%$ of them never expressed gratitude to their parents. Lu's [2] investigation of 500 middle students in a rural area showed that $83.82 \%$ of respondents considered career success as a way of expressing gratitude to parents. These surveys echo other research findings of "little emperors" and "little princesses", a vivid metaphor of the one-child generations [7-13]. What impeded these children's parental love progressing to reciprocal love?

The severity of this situation caused the Chinese Government great concern. It feared that with the decline of filial piety, children, who are the major source of carers for the aged in its underdeveloped social welfare system, would no longer provide this service to the community. The negative consequences of the lack of gratitude in young Chinese generations, such as deteriorating social morality and jeopardising social stability, could be devastating. Therefore, the Chinese Government has, since 2005, launched wave upon wave of massive gratitude education campaigns to rectify the situation at all levels of education from primary school to university across all the provinces and autonomous regions and also in public media. These campaigns involved various activities, such as regular themed class meetings, school commendatory meetings, a theme activity week/month, symposiums, touring report groups (e.g. the Long Marches for Gratitude Education of China on Campus), and the publication of a vast number of books and articles on gratitude [e.g. 7, 8, 10, 11, 14, 15-20]. Of all these activities, school mobilisation assemblies appeared to have the most dramatic effect. Generally, a school mobilisation assembly was held in a school playground on which hundreds of students were marshaled into lines, next to which would be a parent sitting on a stool, often with a bowl of water at their feet. A professional orator was then invited to ascend the front podium and gave a passionate and emotional speech detailing in great length all the sacrifices their parents made for them, such as struggling 
to cook a favourite meal for them when exhausted after coming home from work, worrying about their safety, and picturing how parents' concern for their child's welfare extended to the period of the child's life after their death. Shortly thereafter, most present, including the parents, were moved to tears. As the assembly reached its climax, the students were asked to kneel in front of the parents to say thank-you and/or wash the parents' feet to express their gratitude. Typing in "ganen yanjiang" ("gratitude speech" in Chinese) in Youku (Chinese YouTube), yielded 6,457 video clips [21], over 90 percent of which were scenes of school mobilisation assemblies. However, despite the overwhelmingly moving scenes of school mobilisation assemblies, which have been widely reported in the media as such, these campaigns have been largely ineffectual. This is the feedback I has received from my contact with school principals in China. With a helpless smile, or an exclamation of "what can I do?" these principals explained that their students' behaviours remained the same despite these assemblies. Nothing had changed. In fact, the failed attempt by these assemblies was acknowledged in disguised form by the People's Daily Online [22], the official Chinese newspaper flagship, on $10^{\text {th }}$ December 2015, when it reported that a lack of gratitude in young generations came top in the list of the top ten things that Chinese people lack most. And a sign that appeared to put the brakes on this populous method of gratitude education was also given nearly two months earlier on $16^{\text {th }}$ October 2015 by an editorial in the People's Daily Online [23] warning that the "education" element in gratitude education might become overwhelmed by the extravagances of performance and commercialization, and stressing that gratitude does not have to be presented in public and does not necessarily involve falling on one's knees. By examining the nature of the activities employed in the gratitude education campaigns, it can be easily inferred that the education method that engaged children in these campaigns was moral teaching or moral reasoning. And why did moral teaching or moral reasoning in these gratitude campaigns not succeed as it was designed to?

To address these questions, I will first briefly review the literature on filial piety to examine the conception and measures of filial duty. Then I will elaborate on the nature of gratitude to clarify what kind of gratitude is the focus of this article. After that, a mechanism for gratitude development in children will be outlined by relating morality of justice to parental love, induction and discipline, based on the psychological and sociological theories. This is followed by the discussion of the important role of chores as an active disciplinary measure. Finally, a conclusion about the role of chores in gratitude development in children will be drawn.

\section{Filial Piety}

Filial piety, as a primary Confucian virtue of respect, obedience, and care for one's parents and ancestors, is widely practised in eastern Asia, in countries such as China, Taiwan, Hong Kong, Singapore, Japan, Korea, and Vietnam. In these countries, children are expected to look after their parents in matters of emotion, labour, and finance. A literature review [e.g. 13, 24, 25-27] suggests that filial piety has positive effects, such as intergenerational solidarity, social harmony, and a relief to the social welfare system of a country; but also negative effects, such as self-oppression and placing an economic burden on adult children. By focusing on different aspects of these effects, three major views on filial duties were constructed, namely, the debt theory, the gratitude theory and the friendship theory [28-30] There are also a few variations on these three views, such as the special goods theory [31] stressing a kind of joy and wisdom from childrearing. The debt theory states that grown children are in debt to their parents, but it has an inherent moral dilemma with the unselfishness of parents' sacrifices to their children $[13,26]$. The friendship model then puts filial duties in a voluntary, loving relationship, in which grown children only have duties to their parents that should not impede their autonomy or ability to live a good life [32, 33]; however, this view does not capture the uniqueness of a parent-child relationship. This article is primarily concerned with the gratitude theory in which gratitude arises from parental love and earlier sacrifices throughout the development of a child from birth through childhood and beyond, and which is voluntary, ongoing and open-ended, and can be very demanding.

With regards to how to measure one's filial piety, Yang et al. [34] postulated that filial piety comprises four sequential components: filial knowledge, filial affection, filial intention, and filial acts; and acknowledged that it is not a natural progression to filial acts. Li further points out that, due to the unmeasurable nature of filial thought, filial piety must be reflected in "an act of returning kindness" [35], that is, filial acts. Filial acts can range from an affectionate smile or touch, to daily care and financial support for one's parents. An occasional affectionate smile or touch is easy, but providing daily care and financial support over a long period of time is far more costly; yet the latter may still be required in modern Oriental countries such as China. In sum, in Li's view, filial acts are the sole benchmark for measuring filial piety. Obviously, filial acts must stem from children's grateful disposition towards their parents. But how can such unique gratitude developed in them? Prior to outlining a mechanism for gratitude development, it is necessary to briefly explain how gratitude should be defined.

\section{Gratitude}

There exist two contrasting views on the nature of gratitude. Some tend to regard it as merely an emotion, an episodic disposition [e.g. 36, 37], while others [e.g. 35, 38, $39,40]$ argue that gratitude is a long-term disposition, an affective personality trait, because "[o]ne can be prone to experiencing and certainly expressing gratitude on 
appropriate occasions without necessarily being a grateful person" [41]. While endorsing gratitude as a personality trait, $\mathrm{Li}[42,43]$ further contends that, given a widespread lack of gratitude in one-child generations as a result of parental indulgence, gratitude is not congenital but an acquired disposition. The presence of self-centred "little emperors" and "little princesses" provides abundant empirical evidence for a need for training for gratitude development. The existing research on child development primarily concerns academic achievements, children's autonomy, and positive emotions such as empathy and trust [e.g. 44, 45-52]; there has been no research exploring how to cultivate a long-term grateful disposition in children.

After a brief look at the conception and measures of filial piety and coming to realise that the practice of filial acts of gratitude must be acquired though cultivation, what then is the kind of cultivation required for gratitude development in children? And what mechanism underpins such cultivation?

\section{Morality of Justice}

According to $\mathrm{Li}[42,53-55]$, morality of justice is the conceptual framework of the mechanism for gratitude development in children, which encompasses three correlated and integral dimensions: parental love, induction and discipline. In what follows, the functions of parental love and household chores will be briefly discussed.

First, parental love, as a unique attribute for family, makes a fundamental contribution to gratitude development in children, serving as the seed, not only for the reciprocity of love, but also for other positive emotions such as caring, sympathy, empathy, compassion, generosity, and even trust [40, 56-59], "which in turn has the effect of building that individual's physical, intellectual, and social resources" [56]. Attachment theory [60-69] indicates that attaining or maintaining proximity to a caring mother figure is critically important for the development of mental health in children, and this attachment will be sustained over time, well into adulthood and across generations [70, 71]. A strong prosocial disposition has also been noted in children who have been brought up with parental love [72]. In sum, parental love plays an essential role in gratitude development in children.

Second, induction engages children in moral reasoning with social justice theory that helps them understand why parental love should and needs to be reciprocated with their love. Given the fact that the self-interest predispositions of human beings are psychologically inherent [36, 73, 74], social justice theory provides a sociological solution for subjugating one's self-interest needs and replacing them with moral values [75]. Social justice theory [73, 75-81] states that moral development is primarily based on social justice achieved through balancing different rights, obligations, and benefits, which form the bedrock of social cooperation and harmony. And through balancing diverse rights, obligations and benefits, individuals learn to respect mutual rights and benefits, which in turn lead to a long-term disposition of appreciation of kindness rendered by others, that is, a personality trait of gratitude.

Last but not least, it is discipline that internalises the theoretical knowledge of social justice and eventually makes the reciprocity of parental love with children's love come true. According to Hoffman's internalisation theory [50, 75, 82-84], discipline plays a fundamental role in moral development transforming from heteronomy to autonomy. Given the fact that moral development is counter to the self-interested nature of human beings, it is a painful process [36], and both Piaget [79] and Kohlberg [78, 85] pointed out that the development of moral justice is not automatic, simply occurring in tandem with chronological aging. In particular, moral reasoning will not lead naturally to moral actions when it comes to high cost, such as filial piety that can be very demanding in terms of time, labour, and finance $[13,86]$. For the development of a habitus of morality of justice, childhood is a vital phase; as Aristotle stated, "it is of no little importance what sort of habits we form from an early age - it makes a vast difference or rather all the difference in the world" [36]. "Morality is embedded in and is an outcome of everyday family practices" [87], which serves to be "sobering children into the social fact that growing up means that obligation precedes pleasure" [87]. Therefore, discipline, as an essential measure, is critically important, and parents need to exert constraint on the self-interest tendency of a child. Discipline can, as explained by Blustein, "gradually shift from its position of outward authority to an inner position of self-control" [88].

Having investigated the widespread lack of gratitude in China's one-child generations, it is not hard to conclude that lack of discipline is at the heart of the failure to subjugate these children's self-interest and of the futility of the moral teaching or moral reasoning in China's nation-wide gratitude campaigns. Then what is the best medicine for this issue? Or what are the most effective disciplinary measures for gratitude development in children? Curbing their desires and enforcing rules, such as asking children to bear the negative consequences of their mistakes (if they can), are customarily considered as two major measures of discipline [53], but both of these are of a passive nature. Is there an active disciplinary measure for gratitude development in children?

\section{Chores}

The benefits of engaging children in chores has been well recognised by nearly all researchers studying chores, These benefits include fostering interpersonal skills, responsibility [89-92], educational attainment and career success [93, 94], and mental health, such as empathy [e.g. 95, 96]. However, a review of the literature also shows that no prior studies have explored the role of chores in gratitude development in children.

Chores provide parents with a great active disciplinary measure to internalise morality of justice in their children 
[55]. A recent empirical study by $\mathrm{Li}$ [54] found that chores play a much more important role in disciplining children than passive disciplinary measures such as curbing desires and enforcing rules. Routine chores are laborious, monotonous and boring, and work against the self-concerned nature of children, but are the best medicine for curing this human weakness by developing a sense of social justice. Through parents actively engaging children in routine chores, children will be able to truly absorb the essence of social justice, that rights and benefits should be earned by correspondingly fulfilling obligations, and that there are no rights and benefits in the world without obligations attached to them. Doing chores provides a great opportunity to help children to realise how much love parents hold for and give them. This realisation then replaces the children's view in which they take parental love for granted and even believe that their parents are indebted to them, as held by some of China's one-child generations. By performing routine chores, they can develop a sense of appreciation and gratitude and repay their parents for the parental love they have received. The routine engagement of chores throughout childhood provides parents with a valuable tool to actively discipline their children, thereby habitualising social justice in their inner state.

This argument has been empirically supported by the findings of a number of large-scale investigations. For example, the Aged Care and Family Research Centre of Beijing University in conjunction with the Research Centre of Chinese Economy conducted the Chinese Longitudinal Healthy Longevity Survey (CLHLS) (Zeng, 2015) which randomly selected 22 provinces and cities nationally and paid door-to-door visits to elderly families up to 60,000 times in total in 1998, 2000, 2002 and 2005. Their findings suggested that an adult daughter has a stronger affective bond with old parents than an adult son, and even a son-in-law, under the influence of the daughter, performs more valuable filial acts than a daughter-in-law. A large-scale cross-cultural study [24] also found that adult daughters practised filial piety more than did adult sons among Chinese in Hong Kong and Taiwan. Given the fact that, in their development, a daughter is customarily required to perform many more chores than a son across almost all cultures [97-103], performing chores is the one feature that stands out in the development of gratitude in children.

It cannot be overemphasised that parental love is the source of a child's gratitude, while the development of social justice through induction and discipline, in particular by engaging children in chores, is more of a means for parents to help their child internalise this parental affection. Without parental love, children could see themselves as cheap labour and consider their housework engagement as a commercial trade for their living in a family; this could greatly compromise their feeling of parental love. Without the development of social justice through induction and discipline, in particular by engaging children in chores, they will be spoilt and become as self-centred as some of China's one-child generations. Therefore, parental love, induction and discipline, especially through routine chores, are indispensable cogs in the mechanism for gratitude development in children.

It should also be noted that performing chores might not alone suffice for the development of social justice in children. Other disciplinary measures, such as curbing children's desires and asking children to bear the negative consequences of their mistakes, may also help to instils in children the concept of mutual respect of rights and interests. Parents also need to be aware that excessive housework may impede a child's academic performance [94].

\section{Conclusions}

This article explores the crux of the widespread lack of gratitude in the one-child generations of China and suggests that engaging children in chores is the best medicine for this social and cultural issue. This is because performing routine chores provides a child with an ideal opportunity to internalise social justice, which subjugates the self-interest nature of human beings and eventually transforms one-way parental love into reciprocity of love between parents and a child. In sum, morality of justice, the trinity of parental love, induction and discipline, holds the key to gratitude development in children, in which chores play a major role as an active means of discipline.

Given that nowadays most children spend little time in helping around the house not only in China but also in the West in countries such as the United States of America [e.g. $96,104,105]$, it is important and indeed imperative to raise and enhance parents' awareness of the role of chores in child development for the benefit of families, communities, schools, and governments, and to urge parents to actively engage their children in daily chores.

\section{REFERENCE}

[1] Wang S. Wu shi Ni Baba [I am your Father]. Kunming, China: Yunnan People's Publishing Company; 2002.

[2] Lu T. Survey on gratitude in junior middle school students in rural areas and measures of school's gratitude education (Nongcun Chuzhongsheng Ganen Xianzhuan Diaocha yu Xuexiao Shishi Ganen Jiaoyu Celue Yanjiu) China's Collective Economy. 2009(12):190-1

[3] Li M, Peng B. Survey on gratitude in middle school students, measures and suggestions for gratitude education (Zhongxuesheng Ganen Xianzhuang Diaocha yu Shishi Ganen Jiaoyu Duice yu Jianyi). Basic Education Review. 2011(13): 67-9.

[4] Chen Y, Yang D. Investigation of gratitude in middle school students from a high school in Tangshan city (Zhongxuesheng Ganen Guannian Xianzhuang de Diaocha yu Yanjiu -- yi Tangshan Shiqu Gaozhongsheng Weili). Adolescents' Invention and Creation. 2011(3):44-5. 
[5] Ma X. Survey on gratitude in teacher students (Dui Gaoshi Xuesheng Ganen Xianzhuang de Diaocha Yanjiu). Journal of Chongqing University of Science and Technology(Social Sciences Edition) 2011(1):200-4.

[6] Zhang C. Survey on gratitude to parents in university students -- Sampling Beijing Forestry University students (Dangdai Daxuesheng dui Fumu Ganen Xianzhuang de Diaocha Yanjiu -- Yi Linye Daxuesheng Weili). Theory Research. 2013(22):116-8.

[7] Zhou, Yafeng Xuegei Fumu: Suzao Haizi de Ganenzhixi [Writing to parents: To forge the heart of gratitude for children]. Beijing, China: China Society Press; 2008.

[8] Tang L. Ganen Zaojiu Zhuoyue [Gratitude generates brilliance]. Beijing, China: Blue Sky Press; 2007.

[9] Huang J. Lun Gaoxiao Pinkunsheng Ganen Yishi de Queshi ji Ganen Jiaoyu [Discussion on lacks of a grateful heart and gratitude education for poor students at university]. Journal of Hengshui University. 2011;13(6):103-5.

[10] Du D, He S, Xu H. Gaoxiao Jiating Jingji Kunnan Xuesheng Ganen Yishi de Queshi yu Duice Yanjiu [Lack of gratitude in economically disadvantaged university students and its counter-measures]. Tertiary Education Studies. 2010(02):75-6

[11] Deng J. Weishenme Women Queshao Ganen Yishi? [Why are we short of gratitude?]. Chengdu Business. 2011 May 9;Sect. 5 .

[12] Chen Z, Zou J. Xuehui Ganen, Rang Shijie Chongman Ai [To learn about gratitude is to make the world full of love]. Nanning, China: Guanxi Ethnics Publishing House; 2007.

[13] Li S. "All good is of parents" and its Chinese context. China Report. 2014;50(4):1-12.

[14] Author group for "Student Happy Reading Library". Jingxiang Haizi Yisheng Chengzhang de Ganen Gushi [Gratitude Stories that affecting the lifetime of a child]. Nanchang: Jiangxi Education Press; 2014. 193 p.

[15] Wu P. Ganen Jiaoyu zai Youer Jiaoyu zhong de Zhongyaoxin [The importance of gratitude education in the education of infants]. Happy Family: Education Forum. 2013(2):24-5.

[16] Guan Y. Ganen Jiaoyu [Gratitude Education]. Yangling: Northwest A\&F University Press; 2013. 154 p.

[17] Li L. Ganen Fumu [Gratitude towards parents]. Changsha: Hunan Science \& Technology Press 2014. 150 p.

[18] Bi L. Jiao Haizi Xuehui Ganen de 36 Zhong Fangfa [To teach children the 36 ways of learning how to hold gratitude]. Beijing, China: Petroleum Industry Press; 2007.

[19] Xiaoshan. Ganen [Gratitude]. Beijing, China: Beijing Times Economy Publisher 2006.

[20] Li F, Li J. Bill Gate Gei Qingshaoniang de 12 Tang Ganenke [The twelve lessons for youngsters on gratitude by Bill Gates]. Beijing, China: China City Press; 2007. 260 p.

[21] Youku. Ganen speech. Youku; 2016 [cited 20161 April]; Available from: http://www.soku.com/search_video/q_\%E6 $\% 84 \% 9 \mathrm{~F} \% \mathrm{E} 6 \% 81 \% \mathrm{~A} 9 \% \mathrm{E} 6 \% \mathrm{BC} \% 94 \% \mathrm{E} 8 \% \mathrm{AE} \% \mathrm{~B} 2$ order by_1_limitdate_0?site $=14 \&$ page $=10$.

[22] Gao Y. Zhongguoren Zuique de Shiyang Dongxi: Quefa
Ganen Weilie Diyi [Lack of gratitide ranks first in the ten things that Chinese people lack most]. People's Daily Online. 201510 December.

[23] Qing C. Renmin Wang Ping: Biliang Zhao Xiaozi? Jingti Ganen Jiaoyu Duoru Biaoyanhua Shangyehua [Peopel's Daily Online Editorial: Batch-making filial children? Be alert that gratitude education might lose itself into performance and commercialisation]. People's Daily Online. 2015 16th October.

[24] Ho DYF. Relational orientation in Asian social psychology. In: Kim U, Berry JW, editors. Indigenous psychologies: Research and experience in cultural context. Thousand Oaks, CA: Sage; 1993.

[25] Ho DYF. Filial piety and its psychological consequences. In: Bond $\mathrm{MH}$, editor. The handbook of Chinese psychology. Hong Kong: Oxford University Press; 1996. p. 155-65.

[26] Li S. The moral dilemma and social disadvantages of placing unique emphasis on the filial child. The International Journal of Critical Cultural Studies. 2013;11(1):1-10.

[27] Yeh KH. The beneficial and harmful effects of filial piety: An intergrative analysis. In: Yang KS, Hwang KK, Pederson PB, Daibo I, editors. Asian social psychology: Conceptual and empirical contributions. CT: Praeger; 2003.

[28] Keller S. The limits of loyalty. Cambridge: Cambridge University Press; 2007.

[29] Daniels N. Am I my parents' keeper?: an essay on justice between the young and the old. New York: Oxford University Press; 1988.

[30] Lyons D. The Odd Debt of Gratitude. Analysis. 1969;29(3):6.

[31] Keller S. Four theories of filial duty. The Phlosophical Quarterly. 2006;56(223):254-75.

[32] English J. What do grown children owe their parents? In: Jecker NS, editor. Aging And Ethics. Totowa, NJ: Humana Press; 1992. p. 147-54.

[33] Nicholas D. The friendship model of filial obligations. Journal of Applied Philosophy. 1995;12(1):77-87.

[34] Yang K-S, Yeh K-H, Huang L-L. Social attitudes and behavours towards filial piety: Theory and measure [Xiaodao de Shehui Taidu yu Xingwei: Lilun yu Celiang] The Collected Papers of Institute of Ethonology, Academia Sinica. Taipei: Institute of Ethonology, Academia Sinica; 1989. p. 171-227.

[35] Li S. How to make a grateful child: Reflection on gratitude campaigns in China in recent years. Sage Open. 2014;4(4):1-7.

[36] Aristotle. The ethics of Aristotle: The Nicomachean ethics. Harmondsworth, New York: Penguin; trans. 1976. 383 p.

[37] Williams B. Ethics and the limits of philosophy. London: Fontana; 1985.

[38] Robert RC. The blessings of gratitude. In: Emmons RA, McCullough ME, editors. The psychology of gratitude. Oxford: Oxford University Press; 2004. p. v-xi.

[39] Watkins PC. Gratitude and subjective well-being. In: Emmons RA, McCullough ME, editors. The psychology of gratitude. Oxford: Oxford University Press; 2004. p. 167-92. 
[40] Komter AE. Gratitude and gift exchange. In: Emmons RA, McCullough ME, editors. The psychology of gratitude. Oxford: Oxford University Press; 2004. p. 195-212.

[41] Emmons RA. The psychology of gratitude: An introduction. In: Emmons RA, McCullough ME, editors. The psychology of gratitude. Oxford: Oxford University Press; 2004. p. 3-16.

[42] Li S. Chinese Parents' Role Modeling: Promoting Gratitude. Childhood Education. 2015;91(3):190-7.

[43] Li S. A mechanism for gratitude development in a child. Early Child Development and Care (Routledge). 2015;in press.

[44] Baumrind D. Authoritarian vs. authoritative parental control. Adolescence. 1968;3(11):255-72.

[45] Baumrind D. Current patterns of parental authority. Developmental Psychology. 1971;4(1, Pt.2):1-103.

[46] Chen-Gaddini M. Chinese mothers and adolescents' views of authority and autonomy: A study of parent-adolescent conflict in urban and rural China. Child Development. 2012;83(6):1846-52.

[47] Dornbusch S, Ritter P, Leiderman P, Roberts D, Fraleigh M. The relation of parenting style to adolescent school performance. Child Development. 1987(58):1244-57.

[48] Fuligni AJ, Zhang W. Attitudes Toward Family Obligation Among Adolescents in Contemporary Urban and Rural China. Child Development. 2004;75(1):180-92.

[49] Grusec JE, Goodnow JJ. Impact of parental discipline methods on the child's internalization of values: A reconceptualization of current points of view. Developmental Psychology. 1994;30(1):4-19.

[50] Hoffman ML. Power assertion by the parent and its impact on the child. Child Development. 1960;31(1):129-43.

[51] Maccoby E, Martin J. Socialization in the context of the family: Parent-child interaction. In: Hetherington EM, editor. Handbook of child psychology. New York: Wiley; 1983. p. $1-101$.

[52] Maccoby EE, Martin JA, Hetheringon E. Handbook of child psychology. New York: Wiley; 1983. 1 p.

[53] Li S. A mechanism for gratitude development in a child. Early Child Development and Care (Routledge). 2016;in press.

[54] Li S. Testing scales of parenting practice and filial acts in children and exploring their correlations. In: Howard AR, editor. Psychology of gratitude: New research. Hauppauge, NY: Nova Science; 2016.

[55] Li S. Household chores in gratitude development in children. In: Howard AR, editor. Psychology of gratitude: New research. Hauppauge, NY: Nova Science; 2016.

[56] Fredrickson BL. What good are positive emotions? Review of General Psychology. 1998;2(3):300-19.

[57] McNeely CA, Barber BK. How do parents make adolescents feel loved? Perspectives on supportive parenting from adolescents in 12 cultures. Journal of Adolescent Research. 2010;25(4):601-31.

[58] Fredrickson BL. Positive emotions broaden and build. Advances in Experimental Social Psychology. 2013;47(Journal Article):1-53.
[59] Fredrickson BL. The broaden-and-build theory of positive emotions. Philosophical Transactions of the Royal Society of London Series B: Biological Sciences. 2004;359(1449):1367 -77 .

[60] Bowlby J. Attachment and loss. New York: Basic Books; 1980.

[61] Bowlby J. Attachment and loss: retrospect and prospect. American Journal of Orthopsychiatry. 1982;52(4):664-78.

[62] Bowlby J. Attachment and loss. New York: Basic Books; 1969.

[63] Brenning K, Soenens B, Braet C, Bal S. The role of parenting and mother-adolescent attachment in the intergenerational similarity of internalizing symptoms. Journal of Youth and Adolescence. 2012;41(6):802-16.

[64] Ainsworth M. Object relations, dependency, and attachment: A theoretical review of the infant-mother relationship. Child Development. 1969(40):969-1025.

[65] Ainsworth M. The effects of maternal deprivation: A review of findings and controversy in the context of research strategy. Public Health Papers. 1961(14):97-165.

[66] Ainsworth M. Infancy in Uganda: Infant care and the growth of love. Baltimore: Johns Hopkins Press; 1967.

[67] Ainsworth M. Attachments beyond infancy. American Psychologist. 1989;44(4):709-16.

[68] Bowlby J. Child care and the growth of love. Harmondsworth, England: Penguin Books; 1965.

[69] Steele H, Steele M. Parenting matters: An attachment perspective. In: Mcclain L, Daniel C, editors. What is parenthood?: Contemporary debates about the family. New York and London: New York University Press; 2013. p. 214-33.

[70] Main M, Kaplan N, Cassidy J. Security in infancy, childhood, and adulthood: A move to the level of representation. Monographs of the Society for Research in Child Development. 1985;50(1-2):66-104.

[71] Main M, Goldwyn R. Interview-based adult attachment classifications: Related to infant-mother and infant-father attachment. Developmental Psychology. 1995;19:227-39.

[72] Honig AS. How teachers and caregivers can help young children become more prosocial. In: Chesebrough E, King P, Gullotta T, Bloom M, editors. A blueprint for the promotion of prosocial behavior in early childhood. New York: Kluwer Academic/Plenum Publishers; 2004. p. 51-91.

[73] Hume D. A treatise of human nature. New York, NY: Dent; 1960.

[74] Kohlberg L. Development of moral character and moral ideology. In: Hoffman LW, Hoffman ML, editors. Review of child development research. New York, NY: Russell Sage Foundation; 1964. p. 383-432.

[75] Hoffman ML. Moral internalization, parental power, and the nature of parent-child interaction. Developmental Psychology. 1975;11(2):228-39.

[76] Deigh J. Love, guilt, and the sense of justice. Inquiry. 1982;25(4):391-416. 
[77] Elm DR, Weber J. Measuring moral judgment: The moral judgment interview or the defining issues test? Journal of Business Ethics. 1994;13(5):341-55.

[78] Kohlberg L. The psychology of moral development: The nature and validity of moral stages. San Francisco, CA: Harper \& Row; 1984.

[79] Piaget J. The moral judgment of the child. New York: Free Press; $1965.410 \mathrm{p}$.

[80] Rawls J. A theory of justice. Oxford: Oxford University Press; 1999.

[81] Rest JR. Development in judging moral issues. Minneapolis: University of Minnesota Press; 1979.

[82] Minton C, Kagan J, Levine JA. Maternal control and obedience in the two-year-old. Child Development. 1971;42(6):1873-94.

[83] Schoggen P. Enivronmental forces in the everyday lives of children. In: Barker RG, editor. The stream of behavior: Explorations of its structure \& content. East Norwalk, CT: Appleton-Century-Crofts; 1963. p. 42-69.

[84] Simmons H, Schoggen P. Mothers and fathers as sources of environmental pressure on children. In: Barker RG, editor. The stream of behavior: Explorations of its structure \& content. East Norwalk, CT: Appleton-Century-Crofts; 1963. p. 70-7.

[85] Kohlberg L. Moral stages and moralization: The cognitive-developmental approach In: Lickona $\mathrm{T}$, editor. Moral Development and Behavior: Theory, Research and Social Issues. Holt, NY: Rinehart and Winston.; 1976. p. 31-53.

[86] Bee HL. Lifespan development. New York, NY: HarperCollins College Publishers; 1994.

[87] Ochs E, Kremer-Sadlik T. Introduction: Morality as family practice. Discourse \& Society. 2007;18(1):5-10.

[88] Blustein J. Parents and children: The ethics of the family. New York, NY: Oxford University Press; 1982.

[89] Rogoff B. The cultural nature of human development. Oxford: Oxford University Press; 2003.

[90] Whiting BB, Whiting JWM, Longabaugh R. Children of six cultures: a psycho-cultural analysis. Cambridge, MA: Harvard University Press; 1975. 237 p.

[91] Wingard L. Mentioning homework first in parent-child interactions. Talk and Text. 2006(26):573-98.

[92] White LK, Brinkerhoff DB. Children's work in the family: Its significance and meaning. Journal of Marriage and the Family. 1981;43(4):789-98.

[93] Wilcox KC. The importance of civic responsibility in higher performing middle schools: An empirical study. Education and Urban Society. 2011;43(1):26-41.

[94] Smith C. The origin and expression of achievement-related motives in children. In: Smith CP, editor. Achievement-related Motives in Children. New York, NY: Russell Sage Foundation; 1969. p. 102-50.

[95] Grusec JE, Goodnow JJ, Cohen L. Household work and the development of concern for others. Developmental Psychology. 1996;32(6):999-1007.

[96] Rende R, Prosek J. Raising can-do kids: Giving children the tools to thrive in a fast-changing world. Perigee: Penguin; 2015.

[97] Berndt TJ, Cheung PC, Lau S, Hau K-T, Lew WJF. Perceptions of parenting in mainland China, Taiwan, and Hong Kong: Sex differences and societal differences. Developmental Psychology. 1993;29(1):156-64.

[98] Blair SL. The sex-typing of children's household labor: Parental influence on daughters' and sons' housework. Youth and Society. 1992(24):178-203.

[99] Bui H-T. Elderly caregiving: Daughters, not sons, step up. USA TODAY. 2014 August 19.

[100] Dotinga R. When parents need care, daughters carry the burden: Study. HealthDay. 2014 August 19.

[101] Grigoryeva A. When gender trumps everything: The division of parent care among siblings. The American Sociological Association Annual Meeting; August 16-19; San Francisco: The American Sociological Association; 2014.

[102] Seymour S. Expressions of responsibility among Indian children: Some precursors of adult status and sex roles. Ethos. 1988;16(4):355-70.

[103] Zeng Y. Beijing University Professor Zeng Yi: Better return for peasants at an old age from raising a daughter than a son. Beijig: National Development Research Institute of Beijing University; 2015 [cited 2015 26/11]; Available from: http://comments.caijing.com.cn/20151123/4016274.shtml.

[104] Klein W, Graesch AP, Izquierdo C. Childen and chores: A mised-methods study of children's household work in Los Angeles families. Anthropology of Work Review. 2009; XXX(3):98-109.

[105] Rende R. The developmental significance of chores: Then and now. Brown University Child and Adolescent Behavior Letter. 2015;31(1):1-7. 